\title{
Supraventricular tachycardia diagnosed by smartphone ECG
}

\author{
Ariana Tabing, ${ }^{1}$ Travis Edward Harrell, ${ }^{2}$ Steven Romero, ${ }^{2}$ Gregory Francisco ${ }^{2}$
}

'Department of Internal Medicine, Naval Medical Center San Diego, San Diego, California, USA

${ }^{2}$ Department of Cardiology, Naval Medical Center San Diego, San Diego, California, USA

\section{Correspondence to}

Dr Travis Edward Harrell, travis.harrell@gmail.com

Accepted 23 August 2017

\begin{abstract}
SUMMARY
Diagnosis of paroxysmal supraventricular tachycardia (PSVT) may be difficult due to its episodic nature, which can be brief and self-limited, limiting the ability for clinicians to diagnose the specific rhythm disorder in a timely manner. We present a case of PSVT, which was unable to be diagnosed through typical evaluation with an event monitor despite several years of symptoms. The patient was ultimately diagnosed using the AliveCor Mobile ECG, a smartphone-based ECG device and application, which he purchased himself and captured a typical atrioventricular node re-entrant tachycardia. The patient was then able to email his cardiologist the tracing, which led to an electrophysiology study and successful slow pathway ablation procedure. Smartphone-based technology has the potential to push diagnostic evaluations outside of the healthcare system and empower patients.
\end{abstract}

\section{BACKGROUND}

Timely diagnosis of paroxysmal supraventricular tachycardia (PSVT) is difficult due to its episodic and unpredictable nature. Patients present with abrupt onset of palpitations, lightheadedness, dyspnoea or chest discomfort, which may last only seconds to minutes.

Traditional diagnostic technologies for PSVT include ambulatory ECG devices (eg, Holter monitors), long-term event monitors and implantable loop recorders. ${ }^{12}$ However, studies have shown that the diagnostic yield for the evaluation of palpitations is less than $10 \%-15 \%$ in patients with 24-hour monitoring and 50\%-60\% for conventional event monitors. ${ }^{2}$ External or internal loop recorders or mobile cardiac telemetry for periods of at least 1 week but up to 36 months for internal loop recorders provide the highest diagnostic yield at $70 \%-90 \% .^{2}$

Advances in smartphone technology have enabled wireless, single-lead, real-time ECG recording without the need for bulky monitors, multiple electrodes and leads, or experienced personnel. There are multiple commercially available smartphone ECG monitors including the AliveCor Mobile ECG (figure 1), which our patient purchased.

The AliveCor Mobile ECG allows patients to wirelessly record a $30 \mathrm{~s}$, single-lead ECG. ${ }^{3}$ Hardware components consist of two metal strips attached to a smartphone case. Touching the electrodes with the fingers of both hands completes a circuit comparable to lead I on a traditional ECG.
Data is wirelessly transmitted to a smartphone in real time, resulting rhythm strip, which can be saved, printed or emailed.

\section{CASE PRESENTATION}

A 53-year-old African-American man, former marathoner and retired Navy nurse, presented to our Cardiology Clinic for evaluation of intermittent rapid heartbeat and lightheadedness over the past 10 years. These episodes occurred irregularly, several times a month and lasted 1 to $15 \mathrm{~min}$.

The patient was otherwise healthy and did not take any prescription medications or supplements. He had no family history of cardiovascular disease or sudden cardiac death. The patient drank 2 cups of coffee daily but denied using tobacco or illicit drugs.

Previously, the patient had been prescribed propafenone and metoprolol for the palpitations; however, due to concern over potential adverse effects he had chosen not to take them. A 30 day event monitor was performed 4 months prior to presentation, which was negative.

Vital signs and physical examination were normal.

\section{INVESTIGATIONS}

A 12-lead ECG showed sinus bradycardia but was otherwise normal.

The patient purchased a smartphone-based ECG monitor called AliveCorMobile ECG in its third generation as shown (figure 1). He obtained this device through an online retailer for $\$ 74.99$. On the onset of his symptoms, the patient recorded a single-lead ECG using this device and submitted the tracing to his cardiologist (figure 2).

The device captured a regular, narrow-complex tachycardia at $220 \mathrm{bpm}$ with a short RP interval and retrograde $\mathrm{P}$-wave, suggestive of an atrioventricular node re-entrant tachycardia (AVNRT).

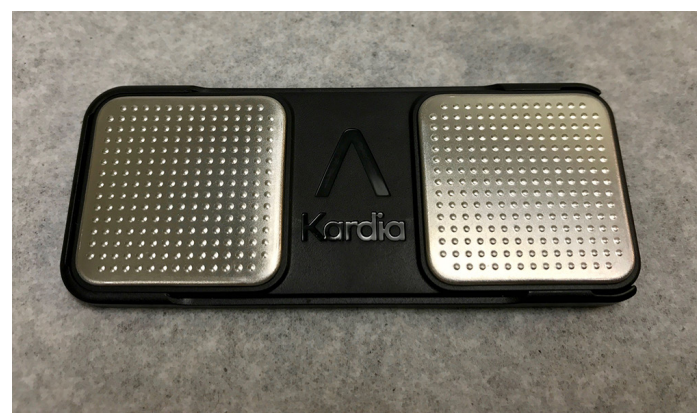

Figure 1 AliveCor Mobile ECG Image. 


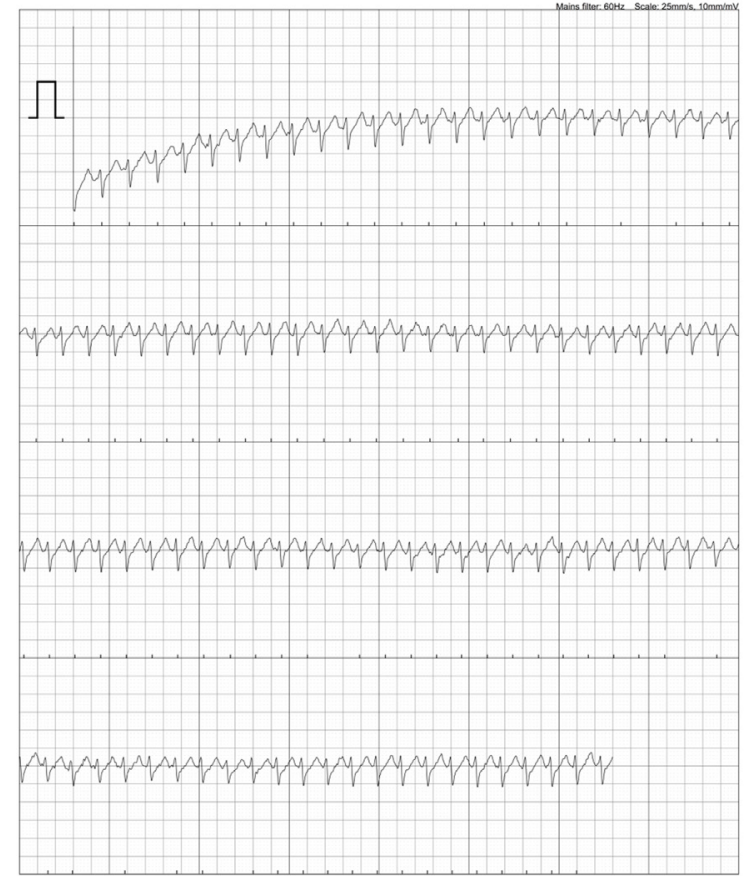

Figure 2 Single-lead ECG tracing of atrioventricular node re-entrant tachycardia from AliveCor Mobile ECG.

Transthoracic echocardiogram demonstrated normal cardiac structure and function.

\section{DIFFERENTIAL DIAGNOSIS}

Supraventricular tachycardia

$\checkmark$ AVNRT

- Atrioventricular Recipricating Tachycardia

- Atrial tachycardia

- Junctional Recipricating Tachycardia

\section{TREATMENT}

The patient underwent an electrophysiology study, which identified typical AVNRT (figure 3), and a slow pathway ablation was performed consistent with current guidelines. ${ }^{45}$

\section{OUTCOME AND FOLLOW-UP}

The patient has had no recurrent episodes of palpitations in nearly 2 years since his ablation.

\section{DISCUSSION}

Our patient was able to achieve a clear diagnosis with this smartphone device after multiple prior diagnostic tests failed to identify his arrhythmia. This case is unique as the patient used a self-purchased smartphone-based device to capture his PSVT instead of using the typical rhythm monitoring devices common in the healthcare setting. Prior reported cases using smartphone-based ECG were still based in the typical healthcare setting in which the provider issued the device to the patient rather than the patients obtaining the technology. ${ }^{3}$ Our case represents the potential direct-to-consumer, or direct-to-patient, application of the technology.

The 2015 American College of Cardiology/American Heart Association/Heart Rhythm Society (HRS) Guidelines Guideline for the Management of Adult Patients With Supraventricular Tachycardia called for more studies on the 'added value' and 'the impact of shared decision-making with patients on outcomes' for personal monitoring innovations such as smartphone-based ECG. $^{5}$

Multiple studies have demonstrated that, compared with 12-lead ECG, smartphone-based ECG accurately detected atrial rate and rhythm, AV blocks and intervals. ${ }^{67}$ Economic analysis demonstrated that using smartphone-based ECG community, outpatient or inpatient screening for atrial fibrillation in elderly adults to be cost-effective. ${ }^{8-10}$ Feasibility studies have shown the potential for full 12-lead ECG via a smartphone-enabled device. ${ }^{11}$ Resource-limited settings may further

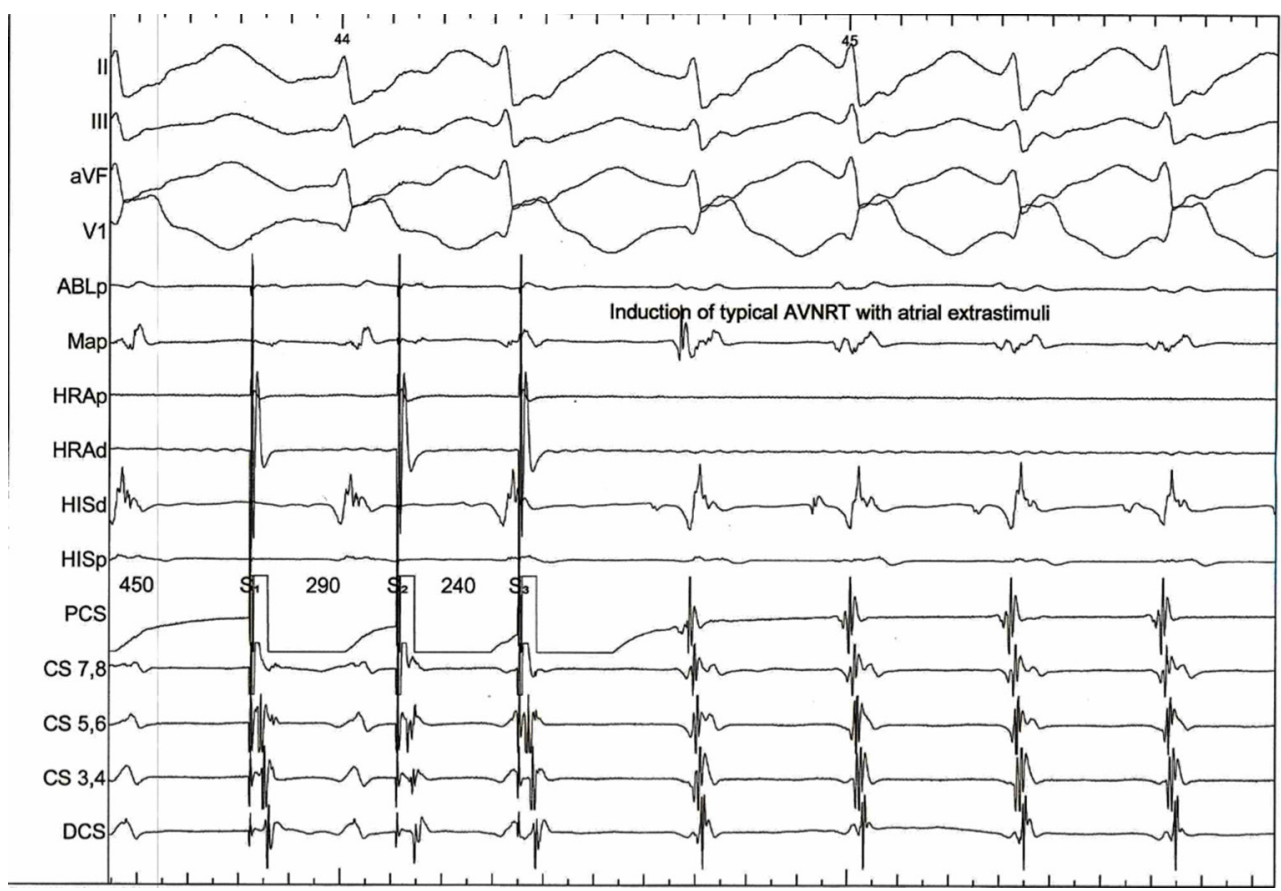

Figure 3 Typical AVNRT from EP study. AVNRT, atrioventricular node re-entrant tachycardia. 
- I had been experiencing sporadic 'PSVT' episodes for approximately 10 years. Initially, I attributed it to anxiety, and would just sit and relax until the episode, subsided. I never sought medical treatment because they were so infrequent. At that time I would say that I experienced an episode perhaps three times annually, so it was not too alarming and it always resolved quickly (less than 1-3 min).

- I am a nurse, so I was not too worried. In the past 2 years, the frequency seemed to increase, upwards of an episode every other month, and I could not associate the increase in frequency with any cause. The increase in episodes increased my concern and I began to worry and become more concerned. I went to see my Primary Care Manager, who referred me to a cardiologist. I presented to cardiology, with only a verbal history. I am a marathoner and have a resting heart rate of 50 beats/minute, and my blood pressure is consistently $110 / 68$. I mention this because when I was seen by providers, I am always asymptomatic. I would receive reassurance, and be dismissed. The office EKGs were always normal.

- I became frustrated, because I wanted to know what was going on with me and I wanted the cardiologists to see an EKG while I was symptomatic. I was asked to wear a Holter monitor, but my episodes were so infrequent that it was not used. I was given an 'event monitor' for 30 days, but I didn't have an episode. I continued to experience my 'PSVT', while on walks alone or at home alone. I noticed that the episodes seemed to increase in both frequency and duration. In the past either using Valsalva techniques, or placing myself in the Trendelenburg positions seemed to work quickly to reverse the PSVT symptoms, but most recently the episodes seemed to respond less to the aforementioned interventions.

- With the increase in episodes and the lack of response to the interventions to ameliorate the symptoms, I began to become more anxious and apprehensive, it was scary! I needed a way to 'show' the cardiologists what was going on with me. My cardiologist suggested I get the 'Alive Cor' monitor and app. I purchased it on Amazon for approx. \$75.00. With the device, I am able to recorded my heart rate whenever I feel symptomatic. Just having the device provided a sense of security, in that I could at least record what was happening and provide a copy via PDF to my provider. Having the 'proof' provided a sense of empowerment. I had physical evidence that something indeed was occurring!

- With the recordings, I was able to show my PCM and cardiologist recordings, and as a result I was ultimately diagnosed with 'AVNRT' and received cardiac ablation. I am glad to have the ability to record any events and provide them to my PCM for evaluation.

Learning points

- Rare self-limited episodes of arrhythmias are often difficult to diagnose with conventional monitors (Holter, 30-day event);

- Smartphone-based ECG may provide an alternative pathway to diagnosis;

- Smartphone-based ECG devices are lower cost than conventional monitors;

- Smartphone-based ECG technology may reduce time to diagnosis via the ability of the patient to send their recorder to the provider in real time.

expand the utility of smartphone-based ECG. ${ }^{12} 13$ There has been considerable clinical research regarding the efficacy of smartphone ECG in the screening, diagnosis and monitoring of arrhythmias. ${ }^{71014}$ The 2017 International Society of Holter and Non-invasive Electrocardiology-HRS expert consensus statement on ambulatory ECG monitoring discusses the role of smartphone-based ECG recording systems in evaluation of patients with symptomatic episodes who are able to activate the monitor. ${ }^{4}$ Additionally, the document describes this as a potentially disruptive technology which may alter the traditional model of ambulatory ECG monitoring. Smartphone-based ECG has the potential to decrease the time to diagnosis as the patient is able to send the ECG recording directly to the provider rather than going through third party companies delaying report until after the monitoring period has ended. In many settings, this may be a delay of days to weeks compared with the smartphone-based ECG. It is possible that this may be a cost-efficient process as well, as the devices are cheaper than traditional event monitor services ( $\$ 180$ per monitoring period at our institution). Limitations of this technology include the need for patient-initiated recording and inability of the device to record the onset of arrhythmias, so this is not appropriate for the evaluation of syncope.
This novel technology expedited successful, definitive treatment for our patient's condition at a small personal investment. This highlights the potential real-world value of this technology for the evaluation of palpitations for patients with persistent symptoms, especially if conventional monitors have not led to a diagnosis. Future studies are being developed to compare smartphone-based ECG with conventional monitors for the evaluation of palpitations with respect to diagnostic accuracy, time to diagnosis and patient and provider preference. ${ }^{15} 16$

Contributors AT and TEH contributed equally to the creation of the manuscript, performed the literature search and identified and edited the images for publication. SR and GF each identified and managed the case, had the initial conception of the case report and edited the manuscript to prepare it publication.

Competing interests None declared.

Patient consent Obtained.

Provenance and peer review Not commissioned; externally peer reviewed.

(C) BMJ Publishing Group Ltd (unless otherwise stated in the text of the article) 2017. All rights reserved. No commercial use is permitted unless otherwise expressly granted.

\section{REFERENCES}

1 Zimetbaum P, Goldman A. Ambulatory arrhythmia monitoring. Circulation 2010;122:1629-36.

2 Steinberg JS, Varma N, Cygankiewicz I, et al. ISHNE-HRS expert consensus statement on ambulatory ECG and external cardiac monitoring/telemetry. Heart Rhythm 2017;2017:e1-39.

3. Verma N, Chicos A, Passman R, et al. "Wireless ECG monitoring: there's an app for that". EP Lab Digest. 2014;14:1, 10-12.

4 Katritsis DG, Boriani G, Cosio FG, et al. European Heart Rhythm Association (EHRA) consensus document on the management of supraventricular arrhythmias, endorsed by Heart Rhythm Society (HRS), Asia-Pacific Heart Rhythm Society (APHRS), and Sociedad Latinoamericana de Estimulación Cardiaca y Electrofisiologia (SOLAECE). Europace 2017;19:465-511.

5 Page RL, Joglar JA, Caldwell MA, et al. 2015 ACC/AHA/HRS guideline for the management of adult patients With supraventricular tachycardia: a report of the American college of cardiology/American heart association task force on clinical practice guidelines and the heart rhythm society. J Am Coll Cardiol 2016;67:e27-115 


\section{Novel diagnostic procedure}

6 Haberman ZC, Jahn RT, Bose R, et al. Wireless smartphone ECG enables large-scale screening in diverse populations. J Cardiovasc Electrophysiol 2015;26:520-6.

7 Tarakji KG, Wazni OM, Callahan T, et al. Using a novel wireless system for monitoring patients after the atrial fibrillation ablation procedure: the iTransmit study. Heart Rhythm 2015;12:554-9.

8 Lowres N, Neubeck L, Salkeld G, et al. Feasibility and cost-effectiveness of stroke prevention through community screening for atrial fibrillation using iPhone ECG in pharmacies. The SEARCH-AF study. Thromb Haemost 2014;111:1167-76.

9 Desteghe L, Raymaekers Z, Lutin M, et al. Performance of handheld electrocardiogram devices to detect atrial fibrillation in a cardiology and geriatric ward setting. Europace 2017:19:29-39.

10 Chan PH, Wong CK, Pun L, et al. Head-to-Head comparison of the alivecor heart monitor and microlife watchBP office AFIB for atrial fibrillation screening in a primary care setting. Circulation 2017;135:110-2.

11 Baquero GA, Banchs JE, Ahmed S, et al. Surface 12 lead electrocardiogram recordings using smart phone technology. J Electrocardiol 2015;48:1-7.
12 Soni A, Earon A, Handorf A, et al. High burden of unrecognized atrial fibrillation in rural India: an innovative community-based cross-sectional screening program. JMIR Public Health Surveill 2016;2:e159.

13 Evans GF, Shirk A, Muturi P, et al. Feasibility of using mobile ECG recording technology to detect atrial fibrillation in low-resource settings. Glob Heart 2017; S22118160:30791-8.

14 Chung EH, Guise KD. QTC intervals can be assessed with the alivecor heart monitor in patients on dofetilide for atrial fibrillation. J Electrocardio/ 2015;48:8-9.

15 Hickey $\mathrm{KT}$, Hauser NR, Valente LE, et al. A single-center randomized, controlled trial investigating the efficacy of a mHealth ECG technology intervention to improve the detection of atrial fibrillation: the iHEART study protocol. BMC Cardiovasc Disord 2016;16:152.

16 Lown M, Yue A, Lewith G, et al. Screening for atrial fibrillation using economical and accurate technology (SAFETY)-a pilot study. BMJ Open 2017;7:e013535.

Copyright 2017 BMJ Publishing Group. All rights reserved. For permission to reuse any of this content visit http://group.bmj.com/group/rights-licensing/permissions.

BMJ Case Report Fellows may re-use this article for personal use and teaching without any further permission.

Become a Fellow of BMJ Case Reports today and you can:

- Submit as many cases as you like

- Enjoy fast sympathetic peer review and rapid publication of accepted articles

- Access all the published articles

- Re-use any of the published material for personal use and teaching without further permission

For information on Institutional Fellowships contact consortiasales@bmjgroup.com

Visit casereports.bmj.com for more articles like this and to become a Fellow 